\title{
Development of polymorphic SSR markers in the razor clam (Sinonovacula constricta) and cross-species amplification
}

\author{
Y.H. Dong ${ }^{1}$, H.H. Yao', C.S. Sun ${ }^{2}$, D.M. Lv' ${ }^{1}$ M.Q. Li ${ }^{1}$ and Z.H. Lin ${ }^{1}$ \\ 'Zhejiang Key Laboratory of Aquatic Germplasm Resources, \\ College of Biological and Environmental Sciences, \\ Zhejiang Wanli University, Ningbo, China \\ ${ }^{2}$ College of Life Sciences, Taizhou University, Linhai, China \\ Corresponding authors: Z.H. Lin / H.H. Yao \\ E-mail: zhihua9988@126.com / yaohanhan1020@126.com
}

Genet. Mol. Res. 15 (1): gmr.15017285

Received August 22, 2015

Accepted October 19, 2015

Published January 26, 2016

DOI http://dx.doi.org/10.4238/gmr.15017285

\begin{abstract}
Next-generation sequencing provides large-scale sequencing data with relative ease and at a reasonable cost, making it possible to identify a large amount of SSR markers in a timely and cost-effective manner. On the basis of the transcriptome database of Sinonovacula constricta obtained by Illumina/Solexa pyrosequencing, 60 polymorphic SSR markers were developed and characterized in 30 individuals. The number of alleles per polymorphic locus ranged from 2 to 7 with an average of 3.75 alleles. The observed and expected heterozygosities varied from 0.050 to 1.000 and from 0.050 to 0.836 , respectively. Nineteen loci significantly deviated from Hardy-Weinberg equilibrium $(P<0.01)$ after Bonferroni's correction for multiple tests. In addition, interspecific transferability revealed that 20 polymorphic loci in Solen linearis were first characterized in this study. To the best of our knowledge, this is the highest number of SSRs in S. constricta and the first report of cross-species amplification. These novel polymorphic SSR markers will be particularly useful for conservation
\end{abstract}


genetics, evolutionary studies, genetic trait mapping, and marker assisted selection in the species.

Key words: Sinonovacula constricta; Expressed sequence tags; Single sequence repeats; Cross-species amplification

\section{INTRODUCTION}

The razor clam Sinonovacula constricta (Lamarck 1818), a member of benthic bivalve species, lives in the lower-to-mid intertidal zones along the coast of the West Pacific Ocean. Because of its excellent flavor and commercial importance, it has become a popular seafood and is the main cultured economic shellfish, with an annual yield of approximately $700,000 \mathrm{t}$ in China. However, with the fast development of clam aquaculture over the past two decades, the wild stocks of $S$. constricta have dramatically decreased due to over-exploitation, and the genetic diversity of cultured populations has also declined (Wang et al., 2005; Yan et al., 2010). Because it is an economically important fishery species, the significant decline of $S$. constricta stocks has led to attention being placed on present knowledge of genetic conservation and stock improvement for natural resource management and sustainable utilization. Molecular markers are useful tools in conservation genetics and permit the analysis of population structure, genetic diversity, and gene flow (Wan et al., 2004).

Microsatellite markers or simple sequence repeats (SSRs) are one of the most powerful markers in genetic research and are used to determine genetic diversity, for paternity assessment, genome mapping, and in association studies. SSRs have been developed in a wide number of bivalve species, such as Zhikong scallop Chlamys farreri (Zhan et al., 2008), Pacific oyster Crassostrea gigas (Li et al., 2011), hard clam Meretrix meretrix (Wang et al., 2011), and blood clam Tegillarca granosa (Dong et al., 2012). Furthermore, expressed sequence tag-derived SSRs (ESTSSRs) can be associated with a function and linked more easily to a phenotypic trait of interest, making them useful for functional diversity studies (Tranbarger et al., 2012). Recently, a large number of ESTs were identified from the $S$. constricta transcriptome using 454 pyrosequencing, providing valuable resources for the efficient characterization of EST-SSR markers (Niu et al., 2013). Although, to date, a total of 70 polymorphic SSRs in S. constricta have been isolated and characterized (Niu et al., 2008; Jiang et al., 2010; Liu et al., 2012; Wu et al., 2014; Ma et al., 2015), only 14 EST-SSRs are available, which are not adequate for genetic studies.

In the current study, we report 60 polymorphic EST-SSR in S. constricta and their crossspecies transferability. These novel SSR markers will be particularly useful for conservation genetics, evolutionary studies, genetic trait mapping, and marker-assisted selection in this species.

\section{MATERIAL AND METHODS}

Genomic DNA was extracted from the adductor muscle of 30 adult individuals of $S$. constricta, collected from Ninghai Zhejiang Province, China, using the standard proteinase digestion and phenol-chloroform extraction method (Sambrook and Russell, 2002). The quality and concentration of total DNA were examined on $1.2 \%$ agarose gel electrophoresis and by the $\mathrm{OD}_{260} /$ $\mathrm{OD}_{280}$ ratio using a NanoVue UV/visible spectrophotometer (GE Healthcare UK Limited, UK). DNA templates were diluted with ultrapure water to obtain a $100 \mathrm{ng} / \mu \mathrm{L}$ final concentration. 
Previously, we sequenced a comprehensive transcriptome of $S$. constricta using the Illumina HiSeq 2000 platform. Putative SSR markers were screened using the SSRHNUTER program (Li and Wan, 2005). Primers flanking microsatellites were designed by the Primer Premier 5.0 software.

PCR amplifications were performed in a $20-\mu \mathrm{L}$ reaction mixture containing $0.5 \mathrm{U}$ Taq DNA polymerase (Takara), 1X PCR buffer, $0.2 \mathrm{mM}$ dNTP mix, $2.5 \mathrm{mM} \mathrm{MgCl}, 0.25 \mu \mathrm{M}$ each forward and reverse primers, and $100 \mathrm{ng}$ template DNA. The PCR was carried out in a Mastercycler Pro $S$ thermal cycler under the following conditions: initial denaturation at $94^{\circ} \mathrm{C}$ for $5 \mathrm{~min}$, followed by 35 cycles of denaturation at $94^{\circ} \mathrm{C}$ for $45 \mathrm{~s}$, the primer-specific annealing temperature (Table 1) for $45 \mathrm{~s}$, and extension at $72^{\circ} \mathrm{C}$ for $45 \mathrm{~s}$ with a final extension at $72^{\circ} \mathrm{C}$ for $7 \mathrm{~min}$. PCR products were separated by electrophoresis on $8 \%$ nondenaturing polyacrylamide gel and visualized by ethidium bromide staining under UV light. Allele sizes were identified by comparing bands with a 20-bp DNA ladder (MBI Fermentas, USA). The characterized polymorphic loci were examined for crossspecies amplification in Solen linearis from Zhoushan City, Zhejiang Province, China, to assess their transferability.

All polymorphic SSR-containing unigenes were searched against the NCBI non-redundant $(\mathrm{Nr})$ protein database and Swiss-Prot database using BLASTx with an e-value of 1e-5. The number of alleles $\left(N_{\mathrm{A}}\right)$, observed heterozygosity $\left(H_{\mathrm{O}}\right)$, expected heterozygosity $\left(H_{\mathrm{E}}\right)$, and polymorphic information content (PIC) were calculated using the CERVUS 3.0 program (Kalinowski et al., 2007). The $P$ value for Hardy-Weinberg equilibrium (HWE) was estimated using Popgene32 (Yeh et al., 2000). All significant levels were adjusted by the sequential Bonferroni's correction for multiple tests (Rice, 1989).

\section{RESULTS AND DISCUSSION}

Based on the 225 SSR-containing unigenes, 124 primer pairs were successfully designed and used to validate the amplification. After optimization of annealing temperature, 84 primer pairs $(67.74 \%)$ cleanly and consistently amplified the expected products. Of the 84 primer pairs, 60 SSR loci were found to be polymorphic in the population of $S$. constricta (Table 1), resulting in a polymorphic percentage of $71.43 \%$, which was similar to that reported by Jiang et al. (2010) $(70.00 \%)$ and higher than that reported by Liu et al. (2012) $(48.28 \%)$. The $N_{A}$ per polymorphic locus ranged from 2 to 7 with an average of 3.75 alleles, which was similar to previous results obtained from EST-SSRs (Liu et al., 2012). The $H_{\mathrm{O}}$ ranged from 0.050 to 1.000 , while the $H_{\mathrm{E}}$ varied from 0.050 to 0.836 (Table 1 ). The mean PIC was 0.439 , ranging from 0.048 to 0.791 . Furthermore, 19 highly polymorphic loci $(\mathrm{PIC} \geq 0.5)$ and 32 moderate polymorphic loci $(0.25<\mathrm{PIC}<0.5)$ were found to be suitable for population genetic analyses. In addition, among the 60 polymorphic loci, 27 $(45 \%)$ identified from annotated genes were expected to be especially valuable for use in functional diversity studies. After Bonferroni's correction for multiple tests, 19 loci were found to significantly depart from HWE $(P<0.01)$.

EST-SSR markers possess higher transferability due to their conservation characteristics when compared with genomic SSRs (Zeng et al., 2010). After cross-species amplification, 20 reliable SSRs could be amplified successfully and displayed polymorphisms in S. linearis, resulting in a transferability rate of $33.33 \%$. The number of alleles of 20 loci in S. linearis ranged from 2 to 7 
Y.H. Dong et al.

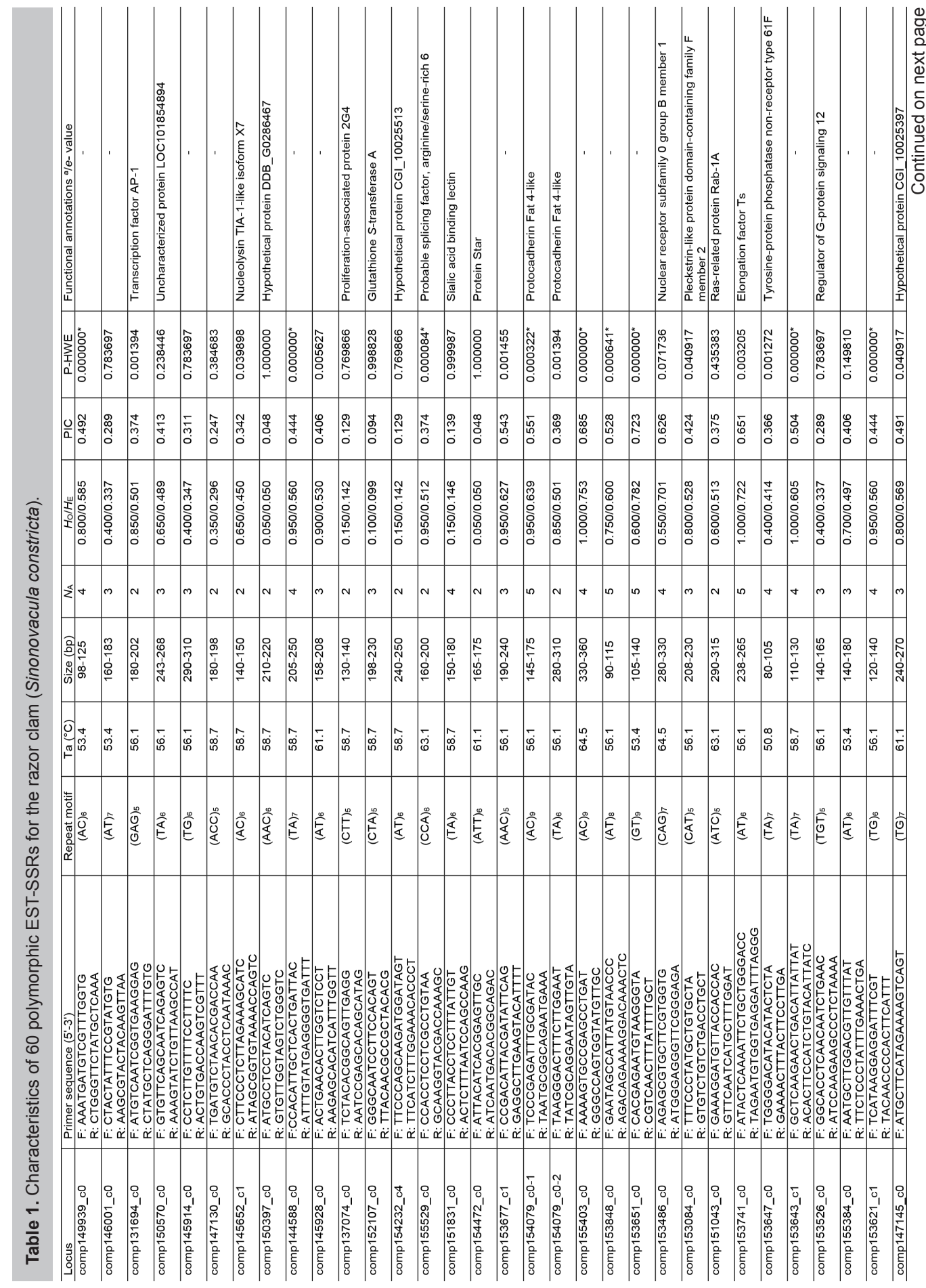




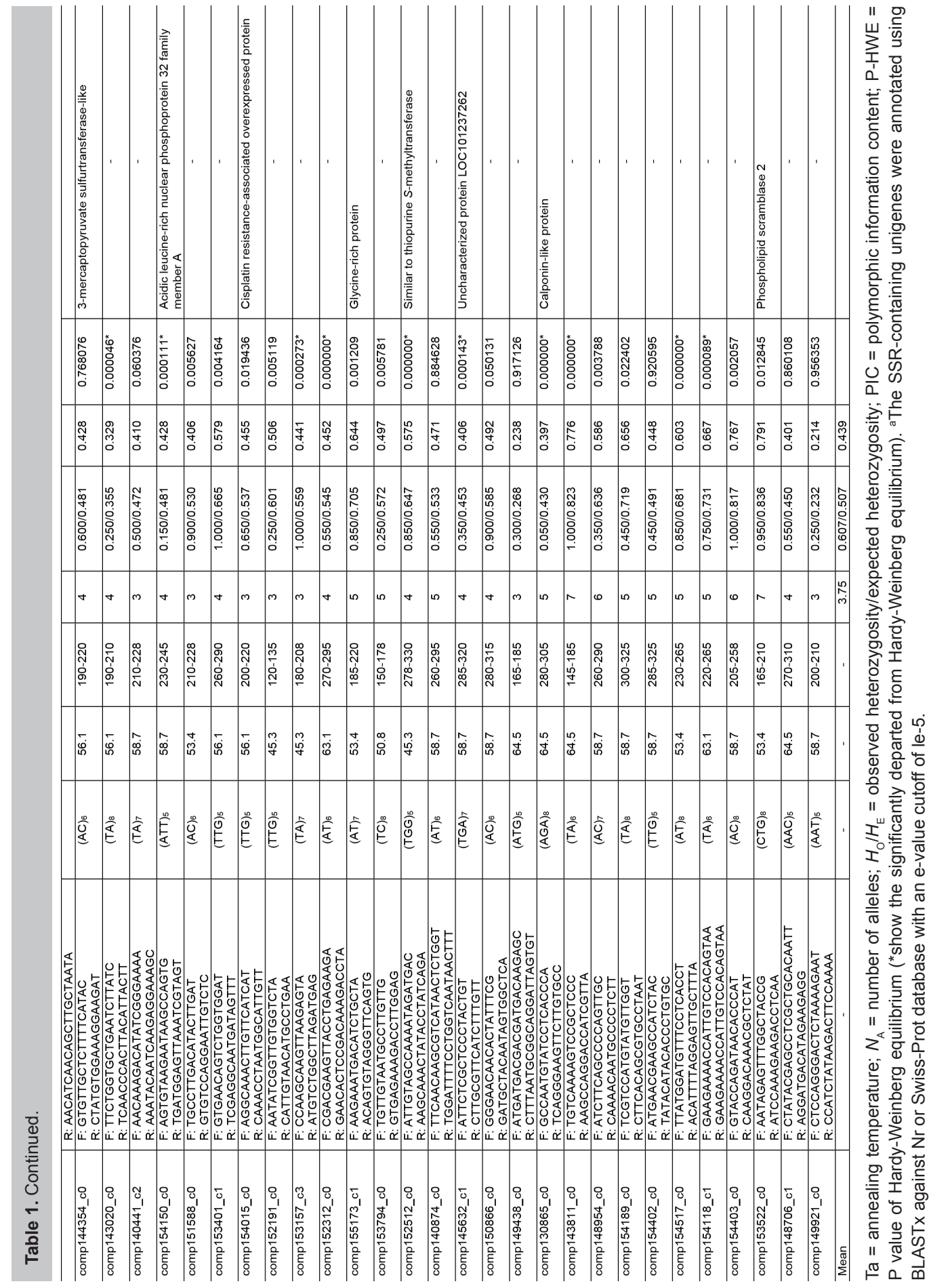


with an average of 3.35 alleles, which was slightly higher than the average number of alleles in $S$. constricta. From the genetic parameters of PIC, $H_{\mathrm{O}}$, and $H_{\mathrm{E}}$, we found that the genetic diversity and heterozygosity of $S$. constricta was higher than that of $S$. linearis (Table 2).

\begin{tabular}{|c|c|c|c|c|c|c|c|c|c|c|}
\hline \multirow[t]{2}{*}{ Locus } & \multicolumn{5}{|c|}{ S. constricta $(\mathrm{N}=30)$} & \multicolumn{5}{|c|}{ S. linearis $(\mathrm{N}=30)$} \\
\hline & $N_{A}$ & $\mathrm{H}_{\mathrm{O}}$ & $H_{\mathrm{E}}$ & PIC & P-HWE & $N_{\mathrm{A}}$ & $H_{0}$ & $H_{\mathrm{E}}$ & PIC & P-HWE \\
\hline comp147130_c0 & 2 & 0.350 & 0.296 & 0.247 & 0.384683 & 4 & 0.222 & 0.386 & 0.351 & 0.015161 \\
\hline comp144354_c0 & 4 & 0.600 & 0.481 & 0.428 & 0.768076 & 2 & 0.833 & 0.500 & 0.368 & 0.003551 \\
\hline comp152191_c0 & 3 & 0.250 & 0.601 & 0.506 & 0.005119 & 2 & 0.833 & 0.513 & 0.374 & 0.006319 \\
\hline comp153643_c1 & 4 & 1.000 & 0.605 & 0.504 & 0.000000 & 3 & 0.611 & 0.465 & 0.389 & 0.373985 \\
\hline comp153647_c0 & 4 & 0.400 & 0.414 & 0.366 & 0.001272 & 3 & 0.389 & 0.338 & 0.300 & 0.830418 \\
\hline comp153794_c0 & 5 & 0.250 & 0.572 & 0.497 & 0.005781 & 7 & 0.778 & 0.722 & 0.677 & 0.903583 \\
\hline comp153157_c3 & 3 & 1.000 & 0.559 & 0.441 & 0.000273 & 4 & 0.222 & 0.303 & 0.280 & 0.083754 \\
\hline comp153486_c0 & 4 & 0.550 & 0.701 & 0.626 & 0.071736 & 2 & 0.944 & 0.513 & 0.374 & $0.000236^{*}$ \\
\hline comp153848_c0 & 5 & 0.750 & 0.600 & 0.528 & 0.000641 & 2 & 0.333 & 0.413 & 0.321 & 0.394021 \\
\hline comp154472_c0 & 2 & 0.050 & 0.050 & 0.048 & 1.000000 & 2 & 0.556 & 0.508 & 0.372 & 0.682107 \\
\hline comp145652_c1 & 2 & 0.650 & 0.450 & 0.342 & 0.039898 & 3 & 0.556 & 0.446 & 0.386 & 0.502284 \\
\hline comp153401_c1 & 4 & 1.000 & 0.665 & 0.579 & 0.004164 & 4 & 0.389 & 0.344 & 0.314 & 0.989777 \\
\hline comp154015_c0 & 3 & 0.650 & 0.537 & 0.455 & 0.019436 & 2 & 0.889 & 0.514 & 0.375 & $0.001473^{*}$ \\
\hline comp153526_c0 & 3 & 0.400 & 0.337 & 0.289 & 0.783697 & 3 & 0.111 & 0.110 & 0.104 & 0.998610 \\
\hline comp145914_c0 & 3 & 0.400 & 0.347 & 0.311 & 0.783697 & 5 & 0.222 & 0.464 & 0.421 & 0.007320 \\
\hline comp154079_c0-2 & 2 & 0.850 & 0.501 & 0.369 & 0.001394 & 3 & 0.222 & 0.208 & 0.190 & 0.976673 \\
\hline comp153677_c1 & 3 & 0.950 & 0.627 & 0.543 & 0.001455 & 2 & 0.667 & 0.457 & 0.346 & 0.043775 \\
\hline comp155403_c0 & 4 & 1.000 & 0.753 & 0.685 & 0.000000 & 4 & 0.722 & 0.618 & 0.581 & 0.105114 \\
\hline comp131694_c0 & 2 & 0.850 & 0.501 & 0.374 & 0.001394 & 5 & 0.556 & 0.451 & 0.396 & 0.992839 \\
\hline comp155529_c0 & 2 & 0.950 & 0.512 & 0.374 & 0.000084 & 5 & 0.611 & 0.735 & 0.684 & 0.211279 \\
\hline Mean & 3.200 & 0.645 & 0.505 & 0.426 & 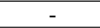 & 3.350 & 0.533 & 0.450 & 0.380 & - \\
\hline
\end{tabular}

$N_{\mathrm{A}}=$ number of alleles; $H_{\mathrm{O}}=$ observed heterozygosity; $H_{\mathrm{E}}=$ expected heterozygosity; PIC = polymorphic information content; $\mathrm{P}-\mathrm{HWE}=\mathrm{P}$ value of Hardy-Weinberg equilibrium.

In summary, we report the highest number of EST-SSRs in S. constricta to date. All of the SSR primers in this study will be useful for conservation genetics, comparative mapping, evolutionary biology, and molecular breeding in the species.

\section{Conflicts of interest}

The authors declare no conflict of interest.

\section{ACKNOWLEDGMENTS}

Research supported by grants from the Modern Agro-Industry Technology Research System (\#CARS-48), the National Infrastructure of Fishery Germplasm Resources Programme (\#2015DKA30470), the Ningbo Natural Science Foundation (\#2010A610008), and the Zhejiang Provincial Top Key Discipline (\#KF20140004).

\section{REFERENCES}

Dong YH, Yao HH, Lin ZH, Zhang LL, et al. (2012). Characterization of 62 polymorphic EST-SSR markers in the blood clam (Tegillarca granosa) and their cross-ampliÿcation in Scapharca subcrenata. Conserv. Genet. Resour. 4: 991-997. http:/l dx.doi.org/10.1007/s12686-012-9691-9

Jiang Q, Li Q, Yuan Y and Kong LF (2010). Development and characterization of 14 polymorphic microsatellite loci in the razor clam (Sinonovacula constricta). Conserv. Genet. Resour. 2: 81-83. http://dx.doi.org/10.1007/s12686-010-9185-6

Kalinowski ST, Taper ML and Marshall TC (2007). Revising how the computer program CERVUS accommodates genotyping error increases success in paternity assignment. Mol. Ecol. 16: 1099-1106. http://dx.doi.org/10.1111/j.1365-294X.2007.03089.x 
Li Q and Wan JM (2005). [SSRHunter: development of a local searching software for SSR sites]. Yi Chuan 27: 808-810.

Li Q, Wang QZ, Qi MJ, Ge JL, et al. (2011). Development, characterization, and inheritance of 113 novel EST-SSR markers in the Pacific oyster (Crassostrea gigas). Genes Genomics 33: 313-316. http://dx.doi.org/10.1007/s13258-011-0021-5

Liu B, Shao YQ, Teng SS, Chai XL, et al. (2012). Characterization, development and utilization of EST-derived microsatellites in Sinonovacula constricta. Oceanol. Limnol. Sin. 43: 132-137.

Ma HT, Jiang HB, Liu XQ, Wu XP, et al. (2015). Polymorphic microsatellite loci for the razor clam, Sinonovacula constricta. Genet. Mol. Res. 14: 145-148. http://dx.doi.org/10.4238/2015.January.15.17

Niu DH, Li JL and Zheng RL (2008). Isolation and sequence characterization of microsatellite DNA in razor clam (Sinonovacula constricta). P. Ocean Univ. China 38: 733-738.

Niu D, Wang L, Sun F, Liu Z, et al. (2013). Development of molecular resources for an intertidal clam, Sinonovacula constricta, using 454 transcriptome sequencing. PLoS One 8: e67456. http://dx.doi.org/10.1371/journal.pone.0067456

Rice WR (1989). Analyzing tables of statistical tests. Evolution 43: 223-225. http://dx.doi.org/10.2307/2409177

Sambrook J and Russell DW (2002). Molecular cloning: A laboratory manual. 3rd edn. Science China Press, Beijing, $463-471$.

Tranbarger TJ, Kluabmongkol W, Sangsrakru D, Morcillo F, et al. (2012). SSR markers in transcripts of genes linked to post-transcriptional and transcriptional regulatory functions during vegetative and reproductive development of Elaeis guineensis. BMC Plant Biol. 12: 1. http://dx.doi.org/10.1186/1471-2229-12-1

Wan QH, Wu H, Fujihara T and Fang SG (2004). Which genetic marker for which conservation genetics issue? Electrophoresis 25: 2165-2176. http://dx.doi.org/10.1002/elps.200305922

Wang DQ, Li TW and Su XR (2005). Comparison of genetic diversity between hatchery stock and wild population of Sinonovacula constricta Lamarck in Xiangshan Bay. J. Fish. Sci. China 12: 138-143.

Wang H, Huan P, Lu X and Liu B (2011). Mining of EST-SSR markers in clam Meretrix meretrix larvae from 454 shotgun transcriptome. Genes Genet. Syst. 86: 197-205. http://dx.doi.org/10.1266/ggs.86.197

Wu XP, Ma HT, Feng YW, Liu XQ, et al. (2014). Isolation of microsatellite loci from razor clam Sinonovacula constricta and transferability to related species. Oceanol. Limnol. Sin. 45: 1330-1337.

Yan HW, Li Q, Liu WG, Yu RH, et al. (2010). Seasonal changes in reproductive activity and biochemical composition of the razor clam Sinonovacula constricta (Lamarck 1818). Mar. Biol. Res. 6: 78-88. http://dx.doi.org/10.1080/17451000903039756

Yeh FC, Yang R, Boyle TJ, Ye Z, et al. (2000). PopGene32, Microsoft Windows-based freeware for population genetic analysis. Molecular Biology and Biotechnology Centre, Univ. of Alberta, Edmonton.

Zeng S, Xiao G, Guo J, Fei Z, et al. (2010). Development of a EST dataset and characterization of EST-SSRs in a traditional Chinese medicinal plant, Epimedium sagittatum (Sieb. Et Zucc.) Maxim. BMC Genomics 11: 94. http://dx.doi. org/10.1186/1471-2164-11-94

Zhan AB, Bao ZM, Hu XL, Wang S, et al. (2008). Characterization of 95 novel microsatellite markers for Zhikong scallop Chlamys farreri using FIASCO-colony hybridization and EST database mining. Fish. Sci. 74: 516-526. http://dx.doi. org/10.1111/j.1444-2906.2008.01554.x 